Research article

Open Access

\title{
Gene expression signatures of morphologically normal breast tissue identify basal-like tumors
}

\author{
Greg Finak ${ }^{1,2,3}$, Svetlana Sadekova ${ }^{1,4}$, Francois Pepin ${ }^{1,2,3}$, Michael Hallett ${ }^{3,5}$, Sarkis Meterissian ${ }^{6,7}$, \\ Fawaz Halwani ${ }^{8}$, Karim Khetani ${ }^{9}$, Margarita Souleimanova ${ }^{4}$, Brent Zabolotny ${ }^{10}$, Atilla Omeroglu ${ }^{9}$ \\ and Morag Park ${ }^{1,2,4,7,11}$
}

\author{
${ }_{1}^{1}$ Molecular Oncology Group, McGill University Health Centre, 687 Pine Ave, West, H3A 1A1, Quebec, Canada \\ 2Department of Biochemistry, McGill University, 3655 Promenade Sir William Osler, H3G 1Y6, Montreal, Quebec, Canada \\ 3McGill Centre for Bioinformatics, McGill University, 3775 University Street, H3A 2B4, Montreal, Quebec, Canada \\ ${ }^{4}$ Breast Cancer Functional Genomics Group, McGill University, 3775 University Street, H3A 2B4, Montreal, Quebec, Canada \\ ${ }^{5}$ School of Computer Science, McGill University, 3480 University Street, H3A 2A7, Montreal, Quebec, Canada \\ ${ }^{6}$ Department of Surgery, McGill University, Montreal, 687 Pine Avenue West, H3A 1A1, Quebec, Canada \\ ${ }^{7}$ School of Medicine, McGill University, Montreal, 687 Pine Avenue West, H3A 1A1, Quebec, Canada \\ ${ }^{8}$ Department of Anatomical Pathology, Sunnybrook Health Sciences Center, 2075 Bayview Avenue, M4N 3M5, Ontario, Canada \\ ${ }^{9}$ School of Pathology, McGill University, 3775 University Street, H3A 2B4, Montreal, Quebec, Canada \\ ${ }^{10}$ Department of Surgery, Grace General Hospital, 300 Booth Drive, R3J 3M7, Winnipeg, Manitoba, Canada \\ ${ }_{11}^{11}$ epartment of Oncology, McGill University, 546 Pine Ave. W, H2W 1S6, Montreal, Quebec, Canada \\ Corresponding author: Morag Park, morag.park@mcgill.ca
}

Received: 17 Jul 2006 Revisions requested: 14 Aug 2006 Revisions received: 21 Aug 2006 Accepted: 20 Oct 2006 Published: 20 Oct 2006

Breast Cancer Research 2006, 8:R58 (doi:10.1186/bcr1608)

This article is online at: http://breast-cancer-research.com/content/8/5/R58

(C) 2006 Finak et al.; licensee BioMed Central Ltd.

This is an open access article distributed under the terms of the Creative Commons Attribution License (http://creativecommons.org/licenses/by/2.0), which permits unrestricted use, distribution, and reproduction in any medium, provided the original work is properly cited.

\begin{abstract}
Introduction The role of the cellular microenvironment in breast tumorigenesis has become an important research area. However, little is known about gene expression in histologically normal tissue adjacent to breast tumor, if this is influenced by the tumor, and how this compares with non-tumor-bearing breast tissue.
\end{abstract}

Methods To address this, we have generated gene expression profiles of morphologically normal epithelial and stromal tissue, isolated using laser capture microdissection, from patients with breast cancer or undergoing breast reduction mammoplasty ( $n$ $=44)$.

Results Based on this data, we determined that morphologically normal epithelium and stroma exhibited distinct expression profiles, but molecular signatures that distinguished breast reduction tissue from tumor-adjacent normal tissue were absent. Stroma isolated from morphologically normal ducts adjacent to tumor tissue contained two distinct expression profiles that correlated with stromal cellularity, and shared similarities with soft tissue tumors with favorable outcome. Adjacent normal epithelium and stroma from breast cancer patients showed no significant association between expression profiles and standard clinical characteristics, but did cluster ER/PR/HER2negative breast cancers with basal-like subtype expression profiles with poor prognosis.

Conclusion Our data reveal that morphologically normal tissue adjacent to breast carcinomas has not undergone significant gene expression changes when compared to breast reduction tissue, and provide an important gene expression dataset for comparative studies of tumor expression profiles.

\section{Introduction}

Despite significant advances in breast cancer treatment, 26\% of patients with early disease develop metastasis and suc- cumb to the disease [1]. None of the current prognostic indicators can reliably predict the outcome for such patients [2-6]. Microarrays have been widely used for expression profiling of

$\mathrm{CSR}=$ core serum response; DTF = desmoid type fibromatosis; $\mathrm{ER}=$ estrogen receptor; $\mathrm{GGH}=$ gamma-glutamyl hydrolase; GITC = guanidinium isothiocyanate; $\mathrm{GO}=$ Gene Ontology; $\mathrm{LCM}=$ laser capture microdissection; $\mathrm{LIMMA}=$ linear models for microarray analysis; $P A M=$ prediction around medoids; $\mathrm{PR}=$ progesterone receptor; $\mathrm{SAGE}=$ serial analysis of gene expression $\mathrm{SAM}=$ significance analysis of microarrays; $\mathrm{SFT}=$ solitary fibrous tumor; TBS-T $=$ tris-buffered saline tween-20. 
breast cancer and other malignancies and, because of their genome-wide nature, they allow for the identification of gene expression changes that have occurred between normal and tumor breast tissues. Using these approaches, several studies have successfully identified breast cancer subtypes and prognostic markers; however, the utility of such markers in the clinic remains open [7-11].

The majority of studies focusing on breast have used heterogeneous material from whole tissue sections with a few exceptions where epithelial cells have been specifically isolated [12]. The presence of loss of heterozygosity in normal stromal breast tissue adjacent to, and distant from, the tumor site has been demonstrated, suggesting that changes in stroma may have occurred [13]. Since surgery is the standard of care, normal cells harboring alterations that may be relevant to cancer progression may remain and, thus, could have important clinical implications.

The normal human breast consists of ductal epithelium and surrounding stroma. The stroma consists of two compartments (intralobular stroma and extralobular stroma), accounts for more than $80 \%$ of the breast volume, and provides nutrition and structural support for the normal epithelium. Carcinoma of the breast, as well as benign hyperplastic conditions, are thought to originate from epithelial cells or progenitor epithelial cells of the terminal duct-lobular unit [14]. However, growing evidence indicates that stroma may play an important role in cancer initiation and progression [15-17]. Little is known regarding gene expression profiles in morphologically normal breast stroma or epithelium adjacent to breast tumor tissue.

At the clinical level, normal tissue is defined as morphologically normal. Laser capture microdissection (LCM) allows one to isolate nearly pure cell populations from a heterogeneous environment, and the material is suitable for microarray gene expression analysis $[12,18,19]$. This approach has allowed the comparison of gene expression profiles between normal human breast epithelium and tumor tissue [12]. Epithelium derived from regions of the breast adjacent to tumor, considered normal by all histological and clinical standards, has been shown to have a distinct gene expression profile from tumor tissue [12]. However, in these cases sample sizes have been small when comparing reduction and adjacent tissue $(n=3$ reduction samples) and, furthermore, stroma was not considered [12]. Thus, knowledge of gene expression patterns in normal tissue would be invaluable to improve the precision of gene expression signatures for poor or good prognosis.

In the present study, LCM was used to dissect normal epithelium and normal stroma derived from patients undergoing breast reduction mammoplasty or surgical treatment of breast cancer. Gene expression profiles reveal that morphologically normal stroma and epithelium from breast cancer patients are not statistically distinct from epithelium and stroma isolated from reduction mammoplasties and do not possess gene expression changes associated with standard clinical characteristics.

\section{Materials and methods Clinical data}

Clinical data were collected for the samples from the Breast Cancer Functional Genomics Group clinical database. Cellular and fibrotic stroma were identified by visual inspection of hematoxylin and eosin stained tissue sections under a microscope. Cellular stroma was defined as tissue with more than 1,000 stroma cells uniformly distributed throughout the field of view (4× magnification), while fibrotic stroma was defined as tissue with less than 800 stroma cells in the field of view (4x magnification) and concentrated primarily around the ducts.

\section{Tissue collection and staining procedures}

All tissue specimens and associated clinical data were collected at McGill University Health Center (Montreal, Canada) between 2000 and 2004 in accordance with the protocols approved by the research ethics committee. Patient consent was obtained on an individual basis for all patients participating in this study. Of 44 patients selected for the study, 34 patients had invasive ductal carcinoma and 10 were healthy donors undergoing reduction mammoplasty. Tissue samples were collected within 30 minutes after surgery, embedded in TissueTek OCT (Somagen, Edmonton, Alberta, Canada) and stored in liquid nitrogen until use. Frozen specimens were cryosectioned in 10-micron slices, stained using a hematoxylin and eosin staining protocol and dehydrated in ethanol and xylene as recommended by the LCM manufacturer (Arcturus, Mountain View, CA, USA). Following dehydration, the slides were air dried for 20 minutes and subjected to LCM. All normal tissues adjacent to tumor were microdissected from regions at least $2 \mathrm{~mm}$ away from tumor margins. Normal and adjacent stroma were sampled exclusively from the extralobular stromal compartment.

\section{LCM, RNA extraction and linear amplification}

All tissues included in this study were re-examined by a clinical pathologist dedicated to the project. Tissue specimens were microdissected into epithelium and stroma using a PixCell lle LCM system (Arcturus). All microdissections were performed within three hours following tissue staining. Total RNA was extracted from each population of microdissected cells using a GITC (guanidinium isothiocyanate) extraction protocol. Briefly, LCM caps were incubated for 5 minutes (room temperature) in $200 \mu \mathrm{l} \mathrm{GITC}$ extraction buffer (4 M GITC, $25 \mathrm{mM}$ sodium citrate $\mathrm{pH}$ 7.0, $0.1 \mathrm{M} \beta$-mercaptoethanol, 0.5\% N-lauroylsarcosine) supplemented with $1.6 \mu \mathrm{l} \beta$-mercaptoethanol. Subsequently, $20 \mu \mathrm{l}$ of $2 \mathrm{M} \mathrm{NaOAc}, \mathrm{pH} 4.0,220 \mu \mathrm{l}$ of watersaturated phenol and $60 \mu \mathrm{l}$ of chloroform-isoamyl alcohol (23:1) were added to the extraction buffer. Following $15 \mathrm{~min}$ utes incubation on ice and centrifugation $(12,000 \mathrm{rpm}, 15$ minutes) the aqueous phase was removed and RNA was pre- 
cipitated with $2 \mu \mathrm{l}$ glycogen (GenHunter, Nashville, Tennessee, USA) and $200 \mu$ isopropanol. Samples were placed at $80^{\circ} \mathrm{C}$ for 30 minutes and centrifuged at $4^{\circ} \mathrm{C}(12,000 \mathrm{rpm})$ for 30 minutes to pellet RNA. Pellets were washed with $70 \%$ ethanol, air dried and subjected to DNAsel treatment (Roche, Basel, Switzerland). DNAsel treatment was performed in the presence of an RNase inhibitor (Invitrogen, Carlsbad, California, USA). Subsequently, samples were re-extracted as described above and re-suspended in $10 \mu \mathrm{l}$ of diethylpyrocarbonate-treated water. RNA was quantified using a RiboGreen assay (Molecular Probes, Carlsbad, California, USA). Subsequently, 2 to $4 \mathrm{ng}$ of total RNA was subjected to two rounds of T7 linear amplification using Ambion Amino Allyl MessageAmp kit (Ambion, Austin, Texas, USA) and labeled with Cy3 and Cy5 dyes according to the manufacturer's procedure. Prior to microarray hybridizations, amplified products were quantified using a spectrophotometer (Nanodrop, Wilmington, Delaware, USA) and subjected to BioAnalyzer to assay for quality (Agilent Technologies, Santa Clara, California, USA).

\section{Microarray hybridization}

Whole Human Genome $44 \mathrm{~K}$ arrays (Agilent Technologies, product G4112A) were used for all experiments. RNA samples (500 ng) were subjected to fragmentation followed by 18 $\mathrm{h}$ hybridization, washing, and scanning (Agilent Technologies, model G2505B) according to the manufacturer's protocol (manual ID \#G4140-90030). Samples were hybridized against Universal Human Reference RNA (Stratagene, ID \#740000, La Jolla, California, USA). Duplicate hybridizations were performed for all samples using reverse-dye labeling.

\section{Immunohistochemistry}

Candidate tissue markers were validated by immunohistochemistry. Frozen tissue sections $(10 \mu \mathrm{m}$ thick) were defrosted at room temperature for $30 \mathrm{~s}$, fixed in acetone (room temperature, 10 minutes) and air dried for 2 minutes. Subsequently, tissue sections were blocked with Peroxidase Blocking Reagent (DakoCytomation, Glostrup, Denmark). Primary antibodies were diluted at 1:50 and 1:15 for anti-c-kit (polyclonal rabbit anti-human CD117, DakoCytomation), and antiCD31 (polyclonal mouse anti-human, DakoCytomation) and applied to the tissue sections for 45 and 15 minutes, respectively. Following a brief wash with TBS-T (tris-buffered saline tween-20), secondary antibodies were applied for 30 and 20 minutes, respectively. Labeled polymer-HRP anti-rabbit (EnVision+ System HRP(DAB), DakoCytomation) was used as a secondary antibody for c-kit staining and labeled polymer-HRP anti-mouse (EnVision+ System HRP(DAB), DakoCytomation) for CD31 staining. After a short wash with TBS-T, DAB Substrat-Chromogen Solution (EnVision $+{ }^{\circledR}$ System HRP(DAB) DakoCytomation) was applied for up to 5 minutes for color development.
Data preprocessing, normalization, and quality control

Microarray data were feature extracted using Feature Extraction Software (v. 7.11) from Agilent with the default parameters. Raw data were uploaded to the NCBI Gene Expression Omnibus database (GEO) and is accessible as data series GSE4823. Outlier features on arrays were flagged by the software. Arrays were required to have an average raw signal intensity of 1,000 in each channel, and a signal to noise ratio above 16 per channel. MvA plots were examined for signs of hybridization or labeling problems. Replicate arrays were required to have a concordance above 0.944 . This level was established empirically using sets of known good replicate arrays in our database.

Data preprocessing and normalization were automated using the BIAS system [20]. Raw feature intensities were background corrected using the RMA background correction algorithm [21,22]. Resulting expression estimates were converted to log2-ratios. Within array normalization was performed using spatial and intensity-dependent loess [23]. Median absolute deviation scale normalization was used to normalize between arrays [24].

\section{Class discovery}

Using class discovery under correlation distance and Euclidean distance metrics, 10,000 bootstrap iterations were performed to assess the significance of the observed clusters using the pvclust package for R[25]. Multidimensional scaling was applied to reduce the dimensionality of the data and permit visualization. Chi-square tests and logistic regression were applied to discrete and continuous variables, repsectively, to test for association with data partitions (clusters). The variables tested included estrogen receptor (ER) status, progesterone receptor (PR) status, lymph node (LN) status, HER2 receptor status, menopause status, age, grade, tumor size, and recurrence.

\section{Class distinction}

Both the linear models for microarray analysis (LIMMA) and significance analysis of microarrays (SAM) algorithms were used to identify differentially expressed gene sets from which to build class predictors [26-29]. Genes from LIMMA were filtered for significance, (false discovery rate adjusted $p$ value $\leq$ $0.01)$, fold change $(\geq 2.0)$, intensity above background $(A>$ 6.0), while genes identified by SAM were filtered by significance $(q \leq 0.3)$, fold change $(\geq 2.0)$, and intensity $(A>6.0)$.

\section{Class prediction}

The prediction around medoids (PAM) algorithm was used to build predictors based on the filtered gene sets [30]. Cross validation was used to test the predictors. This procedure included independent selection of candidate gene sets for each cross validation step. Differentially expressed genes were mapped onto Gene Ontology (GO), and GO terms were 
tested for overrepresentation using the hypergeometric distribution [26].

\section{Assessing patient specific gene expression effects}

We wanted to assess the relative contribution of different factors to the overall variability of gene expression observed in our data. Principal component analysis allows one to succinctly summarize data in a reduced number of dimensions (principal components) [31]. The principal components are ordered by the amount of variation (or signal) in the data that they explain. We performed principal component analysis on the patient matched adjacent stroma and epithelial data. Consecutive sequences of the first 10 principal components were tested for association with clinical characteristics using multivariate analysis of variance (MANOVA). Bonferroni multiple testing correction was applied to the resulting $p$ values [31].

\section{Identification of tissue markers}

LIMMA was used to identify differentially expressed genes between tissues in individual patients and obtain expression estimates for the matched data ([28,32]. Genes not exhibiting differential expression in at least $50 \%$ of samples were excluded from further analysis (B-statistic $>0$ ). A paired t-test was used to identify genes whose patient-matched LIMMA expression estimates were significantly different from zero over the panel of patients (false discovery rate adjusted $p$ value $<1 e-5)$.

\section{Comparison with publicly available cancer datasets}

The expression of gene signatures from a number of publicly available datasets was examined in normal tissue.

The stroma-specific and epithelium-specific gene lists identified by Allinen and colleagues [33] contained 231 and 97 unique genes, respectively, of which 189 and 89 were located (mapped) successfully on the Agilent chip. The activated and inactivated core serum response (CSR) genes from Chang and colleagues [34] contained 228 and 233 genes, respectively, of which 209 and 211 were mapped to the Agilent array. The intrinsic breast cancer gene list of Sorlie and colleagues [35] contained 553 genes, of which 473 were mapped to the Agilent array. The desmoid type fibromatosis (DTF) and solitary fibrous tumor (SFT) specific gene lists from West and colleagues [36] contained 493 and 293 genes, respectively, of which 415 and 238 were mapped to the Agilent array. Genes that were likely to be expressed in normal breast tissue were selected from these gene sets by selecting genes with variance $>1$ in the normal tissue data; $7.3 \%$ of genes in the normal dataset have variance $>1$, and enrichment for high variance genes in the various gene sets was measured by a $\chi^{2}$ goodness of fit test.

Genes from the Agilent whole genome arrays were mapped to the Agilent $24 \mathrm{~K}$ arrays used in the Netherlands cancer dataset [8]. The $24 \mathrm{~K}$ arrays used by Van de Vijver and colleagues [8] contained 24,498 features. Approximately 10,000 contigs on the $24 \mathrm{~K}$ array could not be mapped to GenBank identifiers. Of the remaining 14,339 identifiers, 12,112 were mapped to features on the $44 \mathrm{~K}$ Agilent array. Expression of the genes from the normal tissue signature was then examined in the 295 breast cancer samples from the Netherlands cancer dataset [8].

\section{Accession numbers}

The GEO accession number of the array data series is GSE4823.

\section{Results \\ Identification of stroma- and epithelium-specific gene expression profiles}

To determine the gene expression profiles of morphologically normal epithelium and stroma derived from reduction mammoplasties and breast cancer tissue, we integrated the use of LCM and T7-based RNA amplification with DNA microarrays. LCM provides an accurate means by which to isolate morphologically normal epithelium and stroma adjacent to breast cancer that is free from infiltrating tumor cells. This allows gene expression profiles to be generated from specific cell types rather than whole tissue [18]. LCM was used to isolate matched morphologically normal epithelial and stromal cells from 34 patients with invasive ductal carcinoma, and 10 patients who underwent reduction mammoplasty (Figure 1). Patient and tumor characteristics of the selected invasive ductal carcinoma patients are shown in Table 1 (and Additional file 4). In general, 2 to $5 \mathrm{ng}$ of RNA were extracted from dissected normal epithelial ducts and stroma. We, as well as others, have established that T7 linear amplification preserves the ratios of mRNA abundance between mRNA species, provided all samples undergo the same number of amplification rounds [12,3741].

Expression profiling was performed on cells isolated from morphologically normal epithelial and stromal tissue from 34 cases

\section{Figure 1}

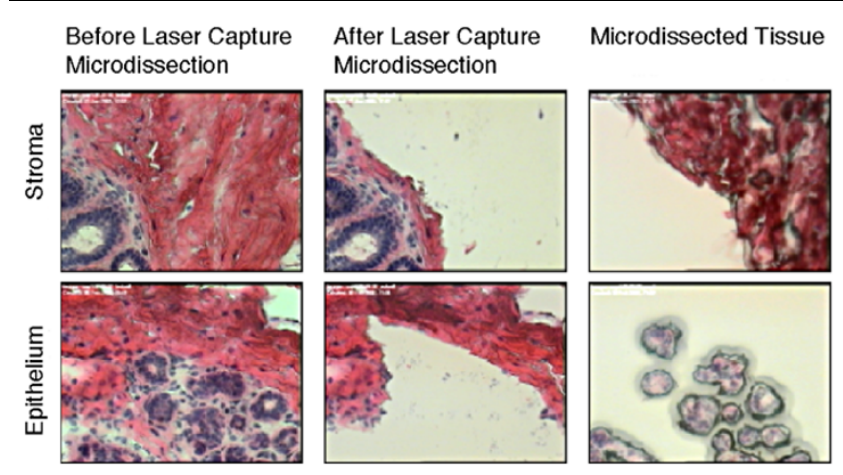

Laser-capture microdissection of epithelium and stroma from normal breast specimens. Frozen tissue sections (10 micron) stained with hematoxylin and eosin. 
Table 1

\begin{tabular}{|c|c|}
\hline Characteristic & Number \\
\hline Adjacent & 34 \\
\hline Reduction & 10 \\
\hline \multicolumn{2}{|l|}{ ER } \\
\hline Positive & 21 \\
\hline Negative & 12 \\
\hline Normal & 10 \\
\hline NA & 1 \\
\hline Total & 44 \\
\hline \multicolumn{2}{|l|}{ HER2 } \\
\hline Positive & 8 \\
\hline Negative & 22 \\
\hline Normal & 10 \\
\hline NA & 4 \\
\hline Total & 44 \\
\hline \multicolumn{2}{|l|}{ PR } \\
\hline Positive & 13 \\
\hline Negative & 20 \\
\hline Normal & 10 \\
\hline NA & 1 \\
\hline Total & 44 \\
\hline \multicolumn{2}{|l|}{ Lymph node status } \\
\hline Positive & 14 \\
\hline Negative & 20 \\
\hline Normal & 10 \\
\hline NA & 0 \\
\hline Total & 44 \\
\hline \multicolumn{2}{|l|}{ Recurrence } \\
\hline Positive & 5 \\
\hline Negative & 38 \\
\hline Normal & 0 \\
\hline NA & 1 \\
\hline Total & 44 \\
\hline \multicolumn{2}{|l|}{ Menopausal status } \\
\hline Post & 16 \\
\hline Pre & 13 \\
\hline Peri & 1 \\
\hline NA & 4 \\
\hline Surgical & 10 \\
\hline Total & 44 \\
\hline Age $($ mean $\pm S D)$ & $52.18 \pm 12.54$ \\
\hline Tumor size (mean $\pm \mathrm{SD}$ ) & $24.76 \pm 14.06$ \\
\hline
\end{tabular}

of invasive ductal carcinoma and 10 cases of reduction mammoplasty using Agilent whole genome arrays. A total of 66 samples were analyzed, of which 32 were isolated from stroma (26 from histologically normal ducts adjacent to tumor, and 6 from reduction mammoplasty), and 34 from epithelium (25 from histologically normal ducts adjacent to tumor, and 9 from reduction mammoplasty) (Table 1). Each of the LCM captured samples was interrogated in duplicate on a $44 \mathrm{~K}$ genomic feature microarray. Since several studies have suggested that normal stroma as well as morphologically normal terminal duct lobular units from cancer patients undergo loss of heterozygosity [42], we first performed a cluster analysis to determine whether the patient-matched stroma and morphologically normal epithelium were similar to those from reduction mammoplasty patients. After normalization, hierarchical clustering was applied to the 66 samples and the complete panel of genes (44 K genome features). Based on gene expression, the stroma and epithelium clustered according to tissue type (Figure 2a). Stroma surrounding histologically normal ducts from tumor specimens and stroma isolated from reduction mammoplasty clustered together. Similarly, morphologically normal epithelium from tumor specimens co-clustered with epithelium from reduction mammoplasties (Figure 2a). We observed similar tissue-specific clustering when using a multidimensional scaling class discovery approach (Figure 3; see Materials and methods). Only three adjacent stroma samples were found to behave as outliers, clustering with epithelial tissue at the whole genome level, an error rate comparable to other large scale microarray data sets (Figures $2 \mathrm{a}$ and 3 ).

To identify the genes responsible for the tissue-specific clustering observed in Figure 2a, class distinction was applied to identify all genes differentially expressed between tissues. Markers were defined based on patient matched stromal and epithelial samples (22 patients and 44 samples; see Materials and methods; Table 1). In total, 883 markers were identified that showed differential expression between matched epithelium and stroma in at least $50 \%$ of individual samples (LIMMA log odds $>0$ ), as well as differential expression between pooled epithelium and stroma samples (false discovery rate adjusted $p$ value 1e-5; Additional file 8). Using these markers, hierarchical clustering was applied to the complete sample set (44 patients, 66 samples), and resolved the samples into epithelial and stromal clusters, including correct classification of the three outlier samples (Figure $2 b$ ). These genes define a normal tissue gene expression signature.

The complete list of GO terms overrepresented by genes in the normal tissue signature is located in Additional file 9 and summarized in Figure 4. Tissue specific genes in the normal signature include known fibroblast, endothelial, and epithelial genes, as well as potentially novel tissue markers. Epitheliumspecific transcripts include genes associated with epithelial cell-cell junctions and the basal lamina, epithelial cell differentiation as well as epidermal growth factor receptor activity 


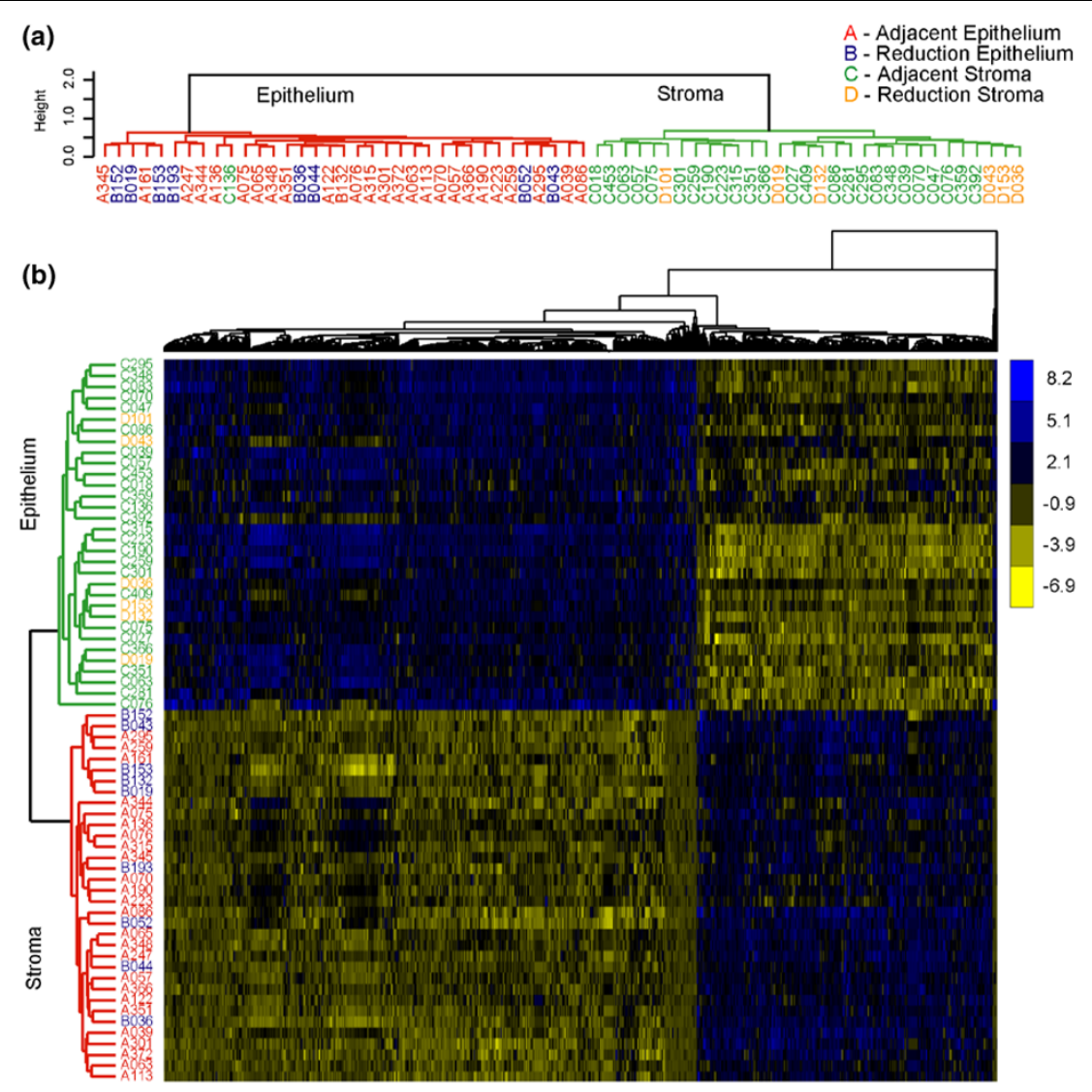

Hierarchical clustering and heatmap showing the segregation of samples by tissue type. (a) Hierarchical clustering of normal tissue samples shows segregation by tissue type (red, adjacent epithelium; blue, reduction epithelium; green, adjacent stroma; orange, reduction stroma). (b) Heatmap showing tissue specific gene expression clusters.

(Table 2). Stroma specific genes included extracellular matrix structural constituents, genes with collagen binding activity, and genes involved in angiogenesis and response to wounding (Table 2, Figure 4). Immunohistochemistry for selected proteins using commercially available antibodies demonstrated epithelial-specific expression of Kit, as well as elevated expression of von Willebrand factor and cd31 in stroma, and confirmed the microarray results (Figure 5).

\section{Normal stroma and epithelial specific gene sets are not predictive of clinical characteristics}

Epithelial and stromal samples were analyzed separately to determine whether there were significant differences within tissue classes between reduction mammoplasty-derived tissue and adjacent morphologically normal tissues isolated from tumor sections. Samples in each tissue class were subjected to hierarchical clustering and subsequent bootstrapping to test for significance using all genes. Although epithelial and stromal samples each show two primary subclusters, these clusters were not statistically significant (Figure 6a,c, respectively). Importantly, adjacent and reduction samples were not associated with the subclusters in either tissue class ( $p=$
0.732 and $p=0.075$, respectively, $\chi^{2}$ test for association). This analysis was repeated using a subset of genes (filtered by coefficient of variation $\geq 4$ ), and showed similar results (data not shown).

Interestingly, morphologically normal adjacent stroma, without reduction mammoplasty samples, was found to consist of two significant subclusters whether using all genes (Figure 6d), or a filtered subset of genes ( $p=1.64 \mathrm{e}-3$, Fisher's exact test). These clusters were found to be associated with stromal 'cellularity' (Figure 7, defined in Materials and methods), which was assessed based on the hematoxylin and eosin staining of the normal tissues ( $p=5.1 \mathrm{e}-3$ and $2.1 \mathrm{e}-4$, respectively, $\chi^{2}$ test for association). A total of 669 genes were identified as differentially expressed between the adjacent stroma clusters using the LIMMA software with a false discovery rate less than 0.01 , a fold change of at least 1.9 , and a B statistic of at least 30. The majority of these genes were elevated in the pauci cellular fibrotic cluster when compared with the cellular stromal cluster. Furthermore, no association was found between clinical characteristics of the primary tumor, and statistically significant subclusters in either tissue class ( $p \leq 0.01$, data not 


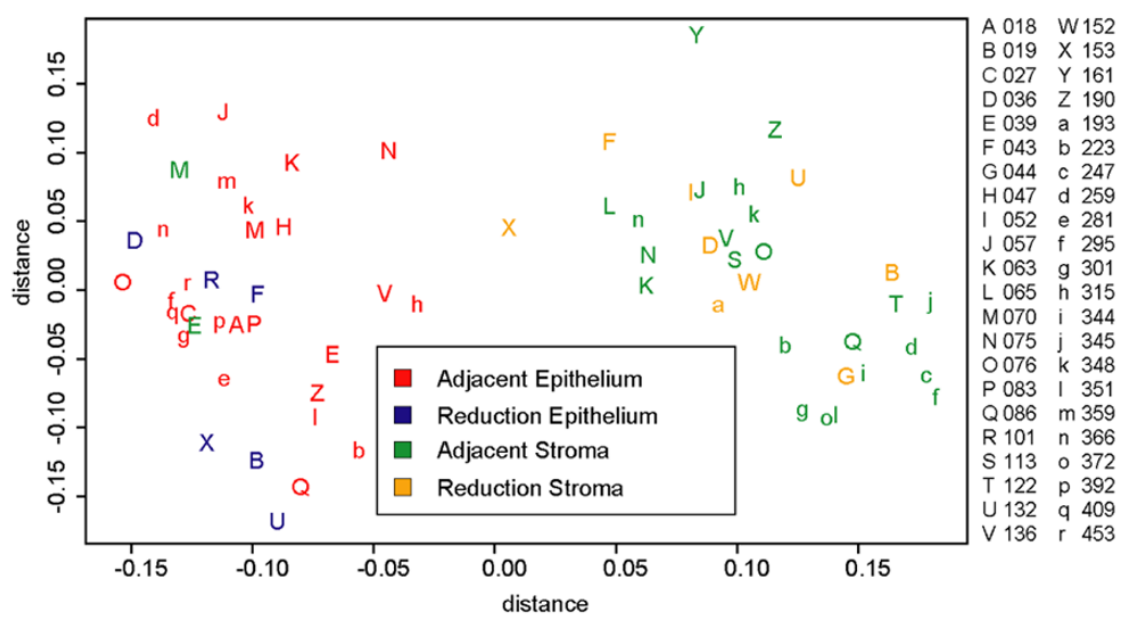

Multidimensional scaling of normal stroma and normal epithelium. Two tissue-specific clusters are observed. Adjacent and reduction tissue do not segregate into separate clusters. The epithelial tissue cluster contains two adjacent stroma sample outliers.

shown) (Additional files 10 and 11). In contrast, no significant clusters were found within morphologically normal adjacent epithelium (Figure 6b, Additional file 3).

To determine whether gene expression patterns in normal breast epithelium or stroma derived from breast cancer patients can predict clinical or pathological features of the corresponding cancers, we applied a class prediction [30] approach and constructed tissue specific predictors for ER, $\mathrm{PR}$, HER2, grade, tumor size, age, menopause status, recurrence, and lymph node status (Additional files 2 and 3). We used cross validation at every step of predictor construction [43], including the initial step of candidate gene selection. None of the predictors had low prediction error or low variance, with an average $50 \%$ mean prediction error by cross validation (Additional files 2 and 3). This analysis demonstrated that any gene expression differences detected in normal epithlium and stroma were neither associated with, nor predictive of, the clinical characteristics of the primary tumors.

Morphologically normal samples from different individuals are expected to show variations in gene expression due to a number of factors, including noise, differences in tissues, interindividual variation, potential clinical differences, and the simple fact that different genes are expressed at different levels. Our goal was to identify the relative contribution of each of these sources of variation to our data (Additional file 12, panel A). Principal component analysis and multivariate analysis of variance revealed that the primary sources of variation in the data could be attributed to differences between tissues (Bonferroni corrected $p=7.9 \mathrm{e}-16$, principal components 2 and 3 ), representing $3.98 \%$ of the variation between genes (Additional file 12, panel B), and differences between individuals (Bonferroni corrected $p=4.9 \mathrm{e}-6$, principal components 3 through 8 ), representing $3.58 \%$ of the variation between genes. The majority of the variation in the data (84.58\%) could be attributed to variations in expression between genes within a single sample. The strong correlation between arrays introduced by the common reference design of our experiment caused this variation to be common across all arrays (Additional file 13). Together, these effects accounted for $92.13 \%$ of the observed variation in the data. The remainder of the variation in gene expression was not associated with any known factors.

\section{The normal epithelium and stroma expression set identify subtypes of breast carcinoma}

The identification of gene expression profiles for morphologically normal stroma and epithelium provide unique datasets that can be used to investigate breast cancer datasets for similarity to the normal tissue profile in order to gain a better understanding of breast cancer expression profiles. When our stroma and epithelium profile was compared to a dataset established by a serial analysis of gene expression (SAGE) approach from dispersed cells from one reduction mammoplasty sample [33], we observed a minimal overlap. Our normal stroma signature (562 unique genes) showed only a 25 gene overlap with that generated by SAGE for a mixture of fibroblast, endothelial and myofibroblast cells (mapped 189 unique genes), and a 2 gene overlap with the epithelium signature (mapped 89 unique genes), whilst our normal epithelium signature (321 unique genes) overlapped by 12 genes with the epithelium signature identified by SAGE. Although the overlaps are statistically significant $(p=1.33 e-15$ and $p=$ $9.07 \mathrm{e}-12$, respectively, hypergeometric test), the relatively low overlap between the signatures may be due to use of only a single patient in the SAGE data when compared to 44 patients in our dataset and our filtering criteria. However, the 
Table 2

Selected tissue markers identified for normal stroma and normal epithelium

\begin{tabular}{|c|c|c|c|c|}
\hline Stromal expression & Epithelial expression & $p$ value & Gene symbol & Gene name \\
\hline 24.41 & 1.00 & $1.02 \mathrm{E}-12$ & SFRP4 & Secreted frizzled-related protein 4 \\
\hline 18.44 & 1.00 & $1.02 \mathrm{E}-12$ & АOC3 & Amine oxidase, copper containing 3 (vascular adhesion protein 1) \\
\hline 17.46 & 1.00 & $3.30 \mathrm{E}-11$ & PTGIS & Prostaglandin 12 synthase \\
\hline 17.11 & 1.00 & $7.97 \mathrm{E}-12$ & TEK & $\begin{array}{l}\text { TEK tyrosine kinase, endothelial (venous malformations, multiple } \\
\text { cutaneous and mucosal) }\end{array}$ \\
\hline 16.68 & 1.00 & $1.02 \mathrm{E}-12$ & IGFBP7 & Insulin-like growth factor binding protein 7 \\
\hline 15.65 & 1.00 & $1.02 \mathrm{E}-12$ & COL1A2 & Collagen, type I, alpha 2 \\
\hline 15.58 & 1.00 & $7.97 \mathrm{E}-12$ & WISP2 & WNT1 inducible signaling pathway protein 2 \\
\hline 14.37 & 1.00 & $1.94 \mathrm{E}-12$ & FBN1 & Fibrillin 1 \\
\hline 13.85 & 1.00 & $1.89 \mathrm{E}-11$ & CD36 & CD36 antigen (collagen type I receptor, thrombospondin receptor) \\
\hline 1.00 & 2.37 & 8.32E-09 & PPP1CB & Protein phosphatase 1 , catalytic subunit, beta isoform \\
\hline 1.00 & 3.07 & $1.30 \mathrm{E}-08$ & К03200 & Human melanoma-associated antigen p97 \\
\hline 1.00 & 3.95 & 2.63E-09 & PERP & TP53 apoptosis effector \\
\hline 1.00 & 4.08 & $7.50 \mathrm{E}-09$ & DDR1 & Discoidin domain receptor family, member 1 \\
\hline 1.00 & 4.75 & $2.11 \mathrm{E}-08$ & $\mathrm{CDH} 1$ & Cadherin 1, type 1, E-cadherin (epithelial) \\
\hline 1.00 & 4.79 & $2.36 \mathrm{E}-07$ & KRT14 & Keratin 14 \\
\hline 1.00 & 5.14 & $1.60 \mathrm{E}-10$ & F11R & F11 receptor, junctional adhesion molecule 1 \\
\hline 1.00 & 6.30 & $1.86 \mathrm{E}-07$ & KIT & v-kit Hardy-Zuckerman 4 feline sarcoma viral oncogene homolog \\
\hline 1.00 & 6.35 & $5.97 \mathrm{E}-08$ & KRTCAP3 & Keratinocyte associated protein 3. \\
\hline 1.00 & 9.07 & $2.92 \mathrm{E}-08$ & ELF5 & E74-like factor 5 (epithelium-specific Ets transcription factor 2) \\
\hline
\end{tabular}

fact that no genes are in common between the epithelial gene set and that of the fibroblast data obtained by SAGE supports the purity of both cell populations in these studies.

To investigate the implication of the expression profiles generated from normal breast tissue in situ to those of tumor related genes in breast cancer, we analyzed the expression of genes in 295 breast carcinomas using a previously published dataset [8]. The normal tissue signature was mapped to 349 genes on the custom $24 \mathrm{~K}$ Agilent arrays used for the cancer study [8]. Hierarchical clustering of the 295 patient samples present in the cancer dataset using the genes in our normal tissue (stroma plus epithelium) signature, revealed two primary clusters of samples (Figure 8). Based on tissue specificity defined by our normal signature, the larger cluster showed enrichment for stroma specific genes ( $p=0.0038$, hypergeometric test) and showed an under-representation of epithelium specific genes ( $p=0.001$, hypergeometric test). However, this enrichment for stroma specific genes was not ubiquitously observed for all of the 257 tumor samples in the cluster, nor was it found to be associated with either the HER2, luminal A or luminal B tumor subtypes (Figures 8 and 9 ). In contrast, the smaller clus- ter showed enrichment for epithelium specific genes ( $p=$ 4.16e-13, hypergeometric test) and under-representation of stroma specific genes ( $p=4.5 e-42$, hypergeometric test).

The smaller of the two clusters consisted of 38 samples, which were identified as ER negative, HER2 negative, and PR negative (Figure 9). This ER/HER2/PR negative cluster was found to express many normal and basal subtype specific genes as defined by Sorlie and colleagues [35], including keratin-5, keratin-17, and gamma-glutamyl hydrolase (GGH). Based on expression of these markers, we identified the samples in this cluster as consisting of basal-like and normal-like cancer subtypes as defined previously [35]. The remaining ER negative samples in the cancer dataset were HER2 positive and were located in the larger sample cluster. Notably, the cluster of basal-like and normal-like samples remained when the data was clustered using only our normal epithelium-specific gene set, whereas the cluster was not observed when normal stroma-specific genes were used in clustering (data not shown). This indicated that the basal subtype-specific patient cluster was enriched in genes expressed in normal epithelium when compared with other tumor subtypes. 


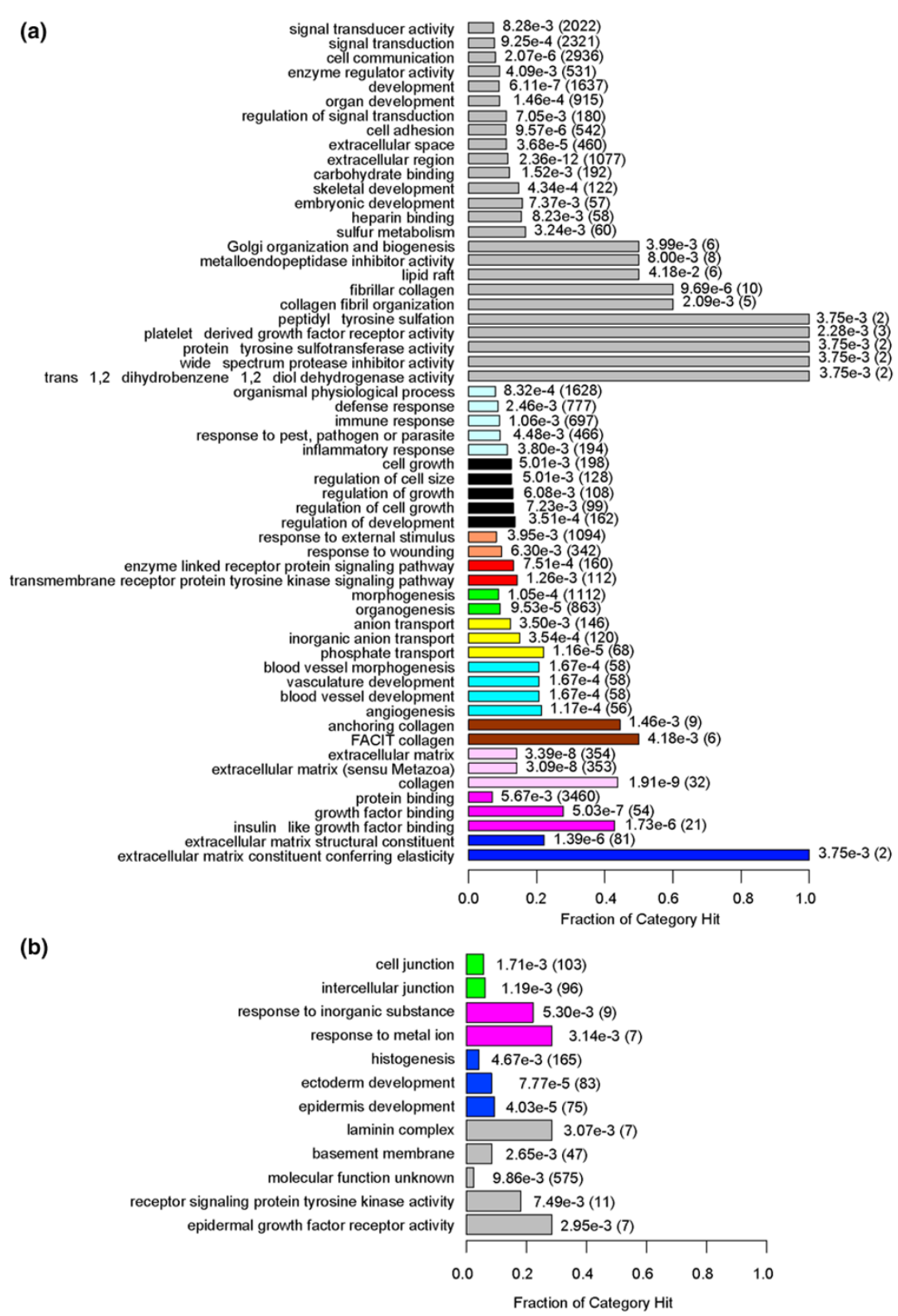

Gene Ontology (GO) categories overrepresented in the normal stroma and normal epithelium gene signatures. (a) GO terms overrepresented by genes expressed in normal stroma. (b) GO terms overrepresented by genes expressed in normal epithelium. Bars represent the fraction of genes in the category that were expressed. Terms of the same color are related in the GO hierarchy (gray terms are unrelated). P values for significance, and the total number of genes in a category are listed after the bar plot.

\section{Normal stroma is similar to DTF tumors and fibroblasts with an inactivated core serum response}

Few datasets have been generated for stroma, and this is the first extensive dataset to be generated from normal stroma. To determine whether our normal stroma data set resembled other gene expression profiles for fibroblasts, a core set of genes shown to be differentially regulated when fibroblasts are stimulated with serum [44] was examined. We identified genes from the CSR profiles that were expressed in normal tissue (Additional files 6 (panel D) and 7) using a variance filtering criteria (see Materials and methods). Of the unstimulated fibroblast genes expressed in normal tissues, 84\% were expressed in stroma, while 16\% were expressed in epithelium, while the majority of genes activated in wounding were not expressed in either tissue (Additional file 6, panel C). These results indicate that both normal adjacent stroma and normal 
Figure 5

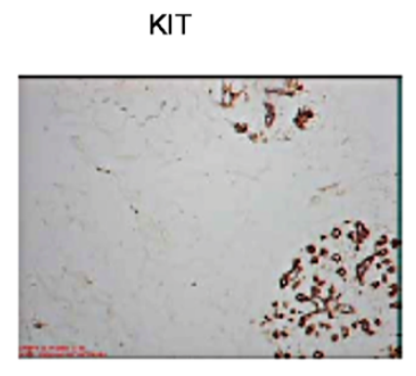

CD31
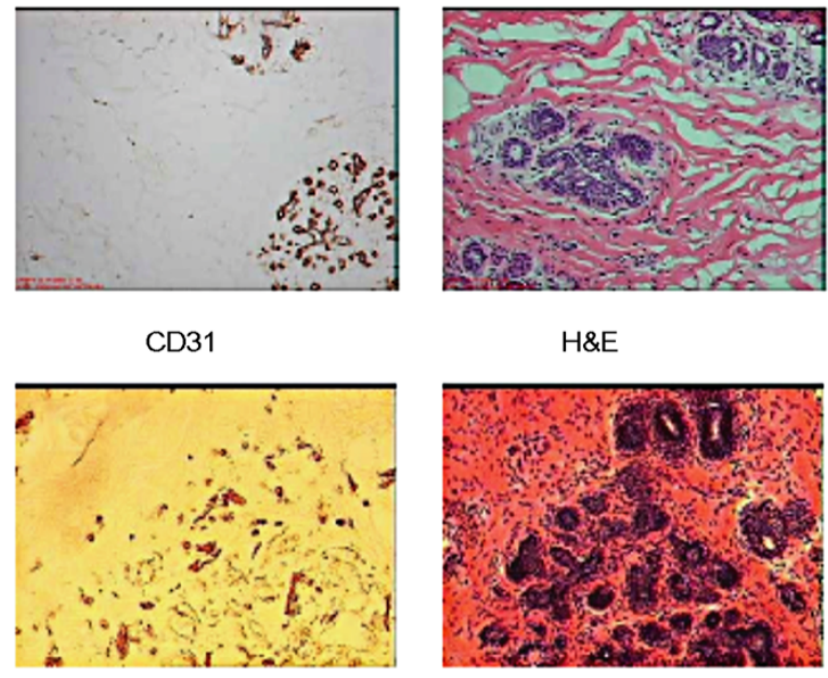

H\&E

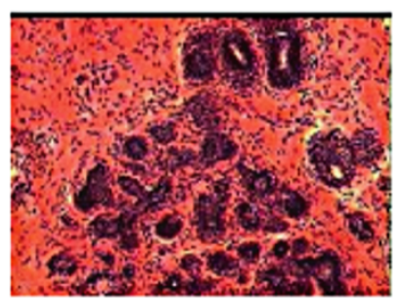

Immunostaining of normal breast tissue with anti-c-kit and anti-CD31. $\mathrm{H} \& \mathrm{E}$, hematoxylin and eosin.

reduction stroma have expression profiles more similar to unstimulated fibroblasts.

To investigate the similarity of our normal stromal profile to that of fibroblastic tumors, normal stroma and epithelium expression profiles were compared to the gene signatures of DTF and SFTs [36]. Normal stroma samples expressed significantly more DTF-specific genes than expected by chance $(p \leq$ $2 \mathrm{e}-16, \chi^{2}$ goodness of fit test), while the number of SFT-specific genes was marginally significant $\left(p=0.038, \chi^{2}\right.$ goodness of fit test) (Additional files 6 (panel A), and 7). Interestingly, normal stroma showed a statistically significant enrichment for expression of DTF-specific genes $(p=2.48 e-5)$ (Additional file 6 , panel B).

\section{Discussion}

Knowledge of the normal breast microenvironment in which a cancer develops is important in understanding cancer biology. However, gene expression patterns of normal stroma and epithelium in human breast cancers have not been extensively studied. Although several studies have identified loss of heterozygosity in morphologically normal breast epithelium [45-47] and stroma $[42,48]$ derived from breast cancer patients, other studies have proposed that these changes were distinct from the co-existing cancer [49]. Hence, it is unclear whether genomic alterations observed in morphologically normal breast tissues represent early precursors of breast cancer, markers of increased risk, or population based polymorphisms. In this paper, we present the most complete study to date of gene expression in normal breast tissues. Using LCM and whole genome microarray analysis we have characterized tis- sue-specific gene expression and identified markers of normal epithelium and stroma.

A primary goal of our study was to establish if a cancer-associated expression signature could be detected in morphologically normal breast tissues obtained from patients with breast cancer. Several approaches were used to address this question. First, we compared gene expression in morphologically normal tissue derived from breast cancer patients to that of healthy individuals undergoing breast reduction surgery. Second, we investigated if the pattern of gene expression in normal breast tissues derived from breast cancer patients was associated with clinical or pathological features of the corresponding cancer. A combination of class discovery, class distinction and class prediction approaches was used to analyze gene expression in microdissected epithelial and stroma samples (Figure 1). The results of this analysis demonstrate that microdissected samples clustered according to tissue type, and not according to the clinical or individual characteristics of the patients (Figures 2, 3 and 6). Moreover, our inability to identify statistically or biologically relevant predictors of the adjacent and reduction classes (Additional files 2 and 3) demonstrates that cancer-adjacent and breast reduction normal tissues have essentially homogeneous expression profiles. Furthermore, variations in gene expression between groups of samples are not associated with clinical characteristics but can be explained by tissue- and patient-specific variability. These data are in agreement with a previous study [12] that demonstrated a lack of significant differences between breast reduction and cancer-adjacent epithelium (three samples) using cDNA microarrays. In addition, our study now demonstrates a lack of significant differences between breast reduction and cancer adjacent stroma.

Notably, ER status, which is often the most important classifier of tumors, both clinically and at the molecular level $[4,10]$, did not associate with any clusters observed in normal stroma or epithelium, nor were we able to identify any predictors for this clinical category. Identical approaches of class distinction, class prediction, and class discovery failed to identify biologically relevant or statistically significant predictors, or clusters associated with any of the other clinical characteristics tested (Additional files 2 and 3). These results suggest that, at the level of global gene expression, there is no significant cancerassociated expression signature detectable in normal breast tissues. We cannot, however, completely rule out the possibility that some subtle changes are present but are obscured by other effects, such as patient variability, or technical limitations.

While we were unable to identify predictors of clinical characteristics, there were genes differentially expressed between some of these clinical characteristics. In most cases the functional categories that were overrepresented consisted mostly of metabolic pathways and processes. Class discovery in nor- 
(a)

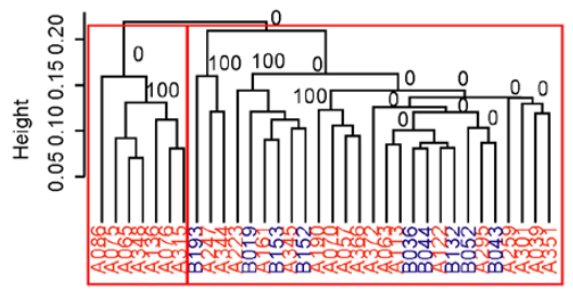

(b)

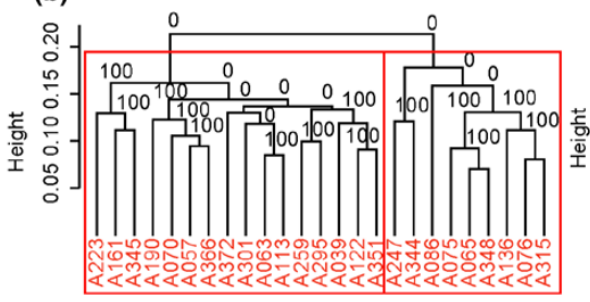

(c)

A - Adjacent Epithelium

$B$ - Reduction Epithelium

C - Adjacent Stroma

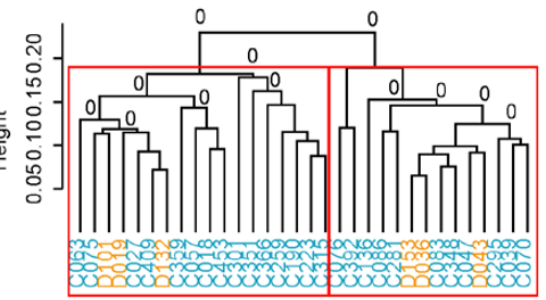

(d)

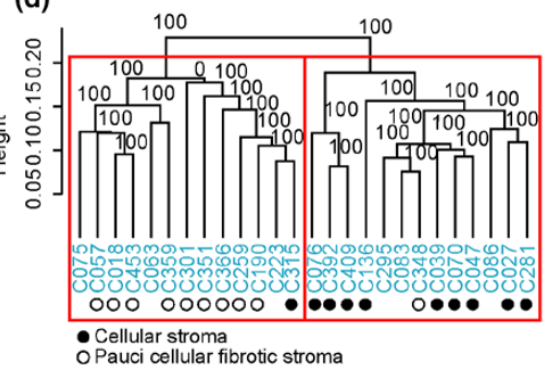

Hierarchical clustering with bootstrapping of adjacent and reduction breast tissues from gene expression data. (a) Hierarchical clustering with bootstrapping of adjacent and reduction epithelium. (b) Histologically normal adjacent and reduction stroma. (c) Histologically normal adjacent epithelium. (d) Histologically normal adjacent stroma. We used 10,000 bootstrap iterations to obtain significance scores for the observed clusters. Nodes are labeled with the percentage of times that the cluster is observed by bootstrapping. Only adjacent stroma showed statistically significant clusters at the top level. Red boxes indicate the top-level clusters that were tested for association with clinical characteristics of the samples.

Figure 7
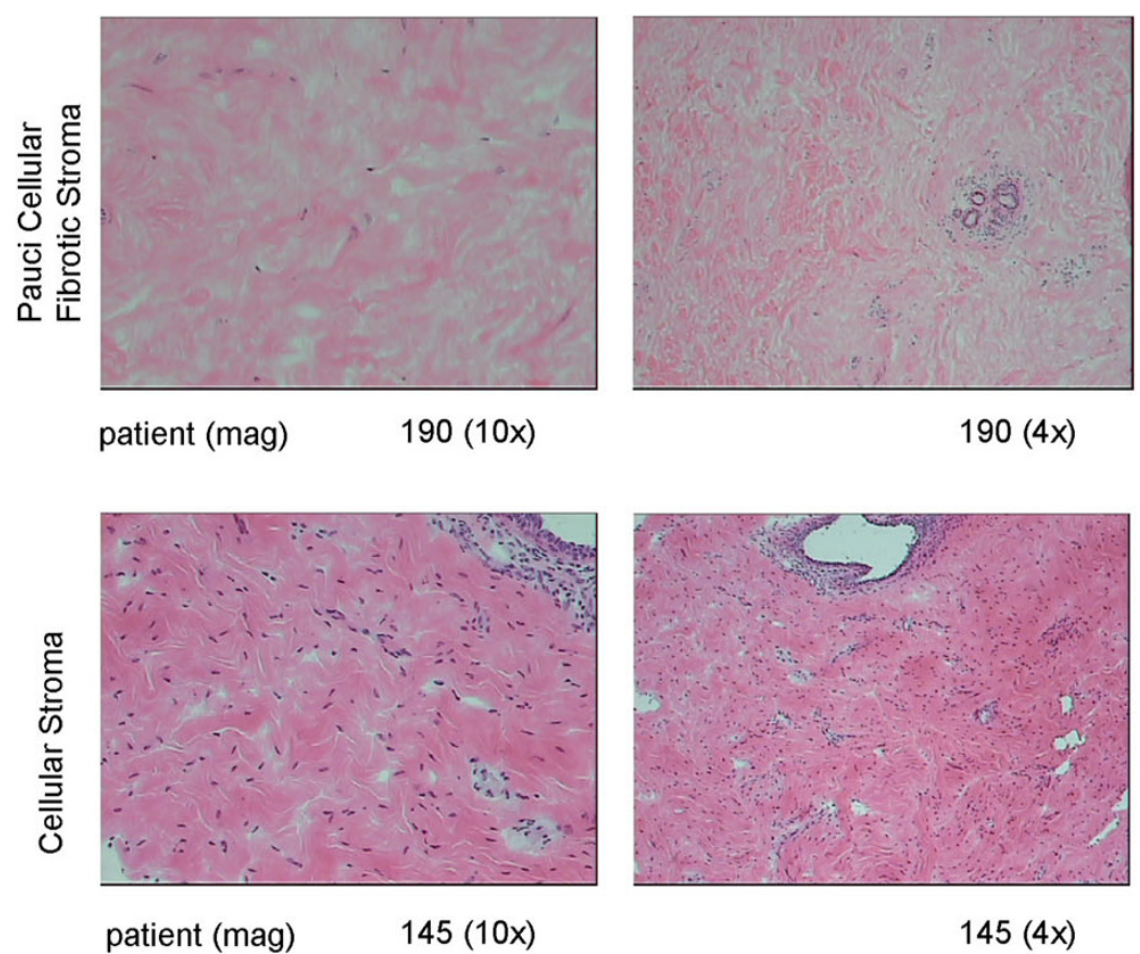

Images of pauci cellular fibrotic and cellular stroma sections from selected patients. Images were taken at $4 \times$ and $10 \times$ magnification. 


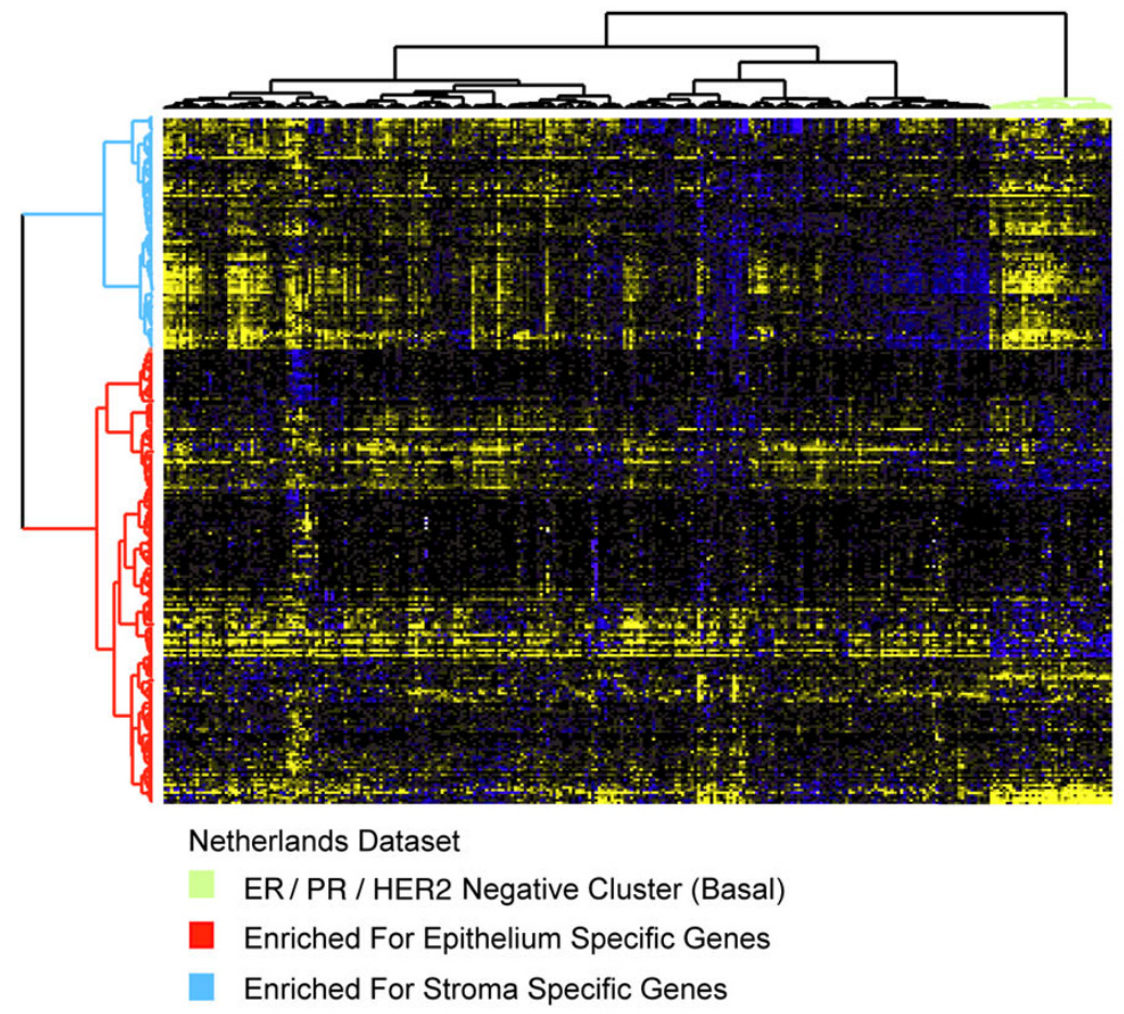

Heatmap of a cancer dataset [8] clustered using the normal gene signature. This signature identifies a distinct cluster of 38 estrogen receptor (ER)/ progesterone receptor (PR) negative, HER2 negative samples corresponding to the basal breast cancer subtype [35]. Elevated expression of normal stroma-specific genes appears in a portion of the lumenal and HER2 positive tumors, although this expression does not correlate with the known molecular subtypes of breast cancer.

mal adjacent stroma revealed two statistically significant clusters associated with stromal cellularity. While we were unable to identify a predictor of stromal cellularity, the differentially expressed genes identified in the class distinction were overrepresented in a number of interesting functional categories, including branching morphogenesis, endocytosis, neurogenesis, and patterning of blood vessels. For example, NOTCH4, a receptor for the Notch pathway that has been shown to inhibit angiogenesis [50], was elevated in the pauci cellular fibrotic stroma cluster when compared to the higher cellularity stroma, while JAG1, a Notch ligand shown to induce angiogenesis in some head and neck tumors [51], was elevated in highly cellular stroma compared to pauci cellular fibrotic stroma. Since we have been careful to sample stroma from the extralobular compartment, it is unlikely that these differences represent extralobular and intralobular stroma. However, we cannot rule out that these may be differences between stromal compartments that have previously not been identified based on morphology.

Comparison of our data to published data sets reveals the similarity of normal stroma and epithelium expression signatures with previously published gene expression profiles of epithe- lium and collective fibroblasts, endothelium, and myofibroblasts isolated from reduction mammoplasty samples [33]. Previous studies have examined the gene expression of cultured fibroblasts in response to serum and demonstrated that this expression program resembled that of a wound response [44] as well as expression profiles from tumors with fibroblastic features [36]. The serum/wound response expression profile was predictive of metastasis and progression in several carcinomas. Our normal breast stroma profile exhibits an expression pattern similar to unstimulated fibroblasts [44,52] and demonstrates that DTF tumors are more related to normal stroma than a SFT signature [36]. Since a DTF tumor profile has been shown to be associated with favorable outcome in breast tumors [36], the enrichment for DTF genes in our normal stroma profile is consistent with this finding.

Notably, clustering of a large breast cancer dataset [8] with the normal stroma and epithelium profile identified two significant clusters of samples (Figure 8). The smaller of the two clusters consisted of 38 samples, which were all identified as ER negative, HER2 negative, and PR negative. This cluster expressed genes specific to basal-like and normal-like cancer subtypes, including keratin-5, keratin-17, and GGH. The 

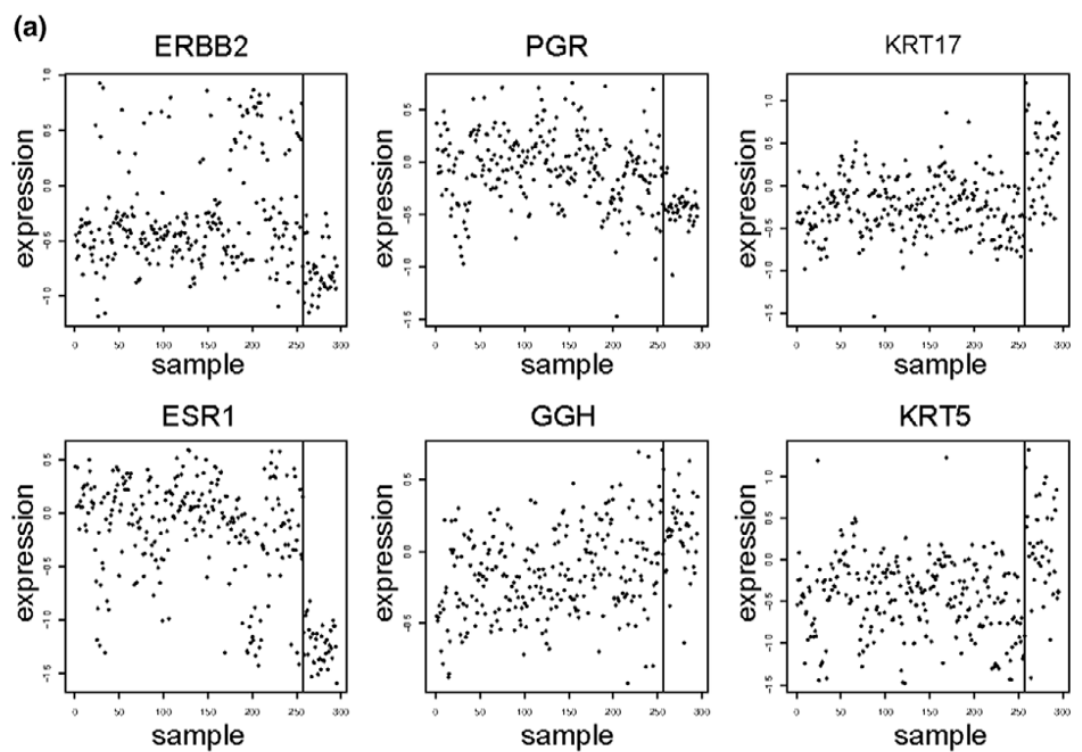

(b)

ERBB2
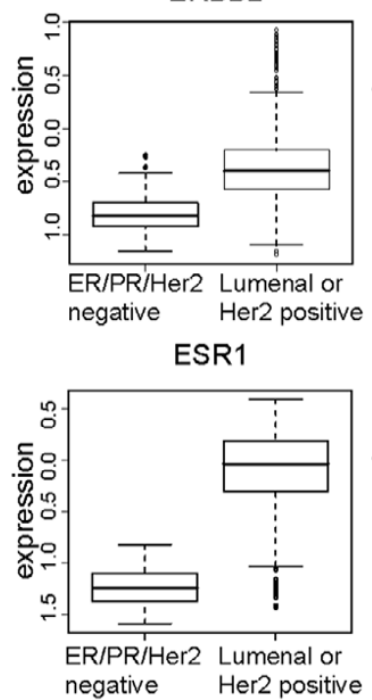

PGR
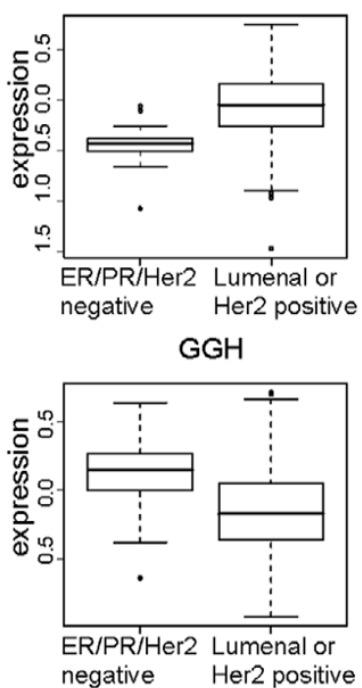

KRT17
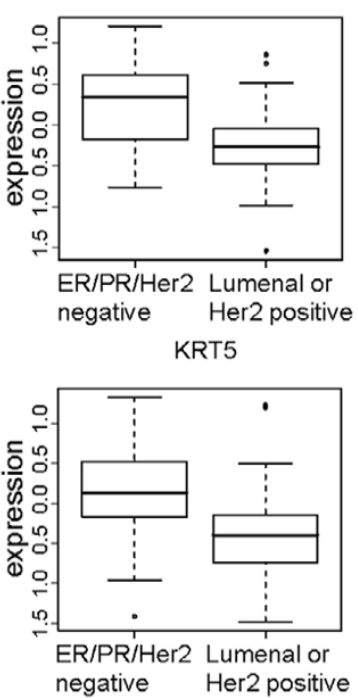

Expression of selected subtype specific markers in the breast cancer dataset [8]. (a) The $y$-axis shows the expression level of the gene, while the $x$ axis identifies each sample, ordered as in Figure 8. The vertical line shows the separation between sample clusters found in Figure 8. The right-most cluster shows decreased expression of estrogen receptor (ESR), HER2, and progesterone receptor (PGR) in most samples, and increased expression of keratin (KRT) 5 and gamma-glutamyl hydrolase (GGH). These markers are indicative of a mixture of basal-like and normal-like tumor subtypes. (b) Box plots showing the distributions of expression for subtype markers in the two observed clusters.

remaining ER negative samples were contained within the larger cluster of 266 samples. This cluster was composed of ER negative/HER2 positive, and ER positive/HER2 negative samples, which are characteristic of HER2 positive and luminal cancer subtypes, respectively $[11,35]$. Clustering of the cancer data using only epithelium specific genes led to repeated observation of a distinct basal-like cluster, whereas clustering using only stroma-specific genes led to co-cluster- ing of the basal-like, ER positive, and HER2 positive tumors. This is in contrast to a recent report showing successful prognostic prediction in breast tumor microarray data using, amongst others, a stroma based signature [53]. The stroma based predictor used in that study was the wound response signature (similar to the CSR response signature), which we have shown is not expressed in normal stroma. Consequently, the predictive genes of the CSR (and wounding) signature are 
Figure 10

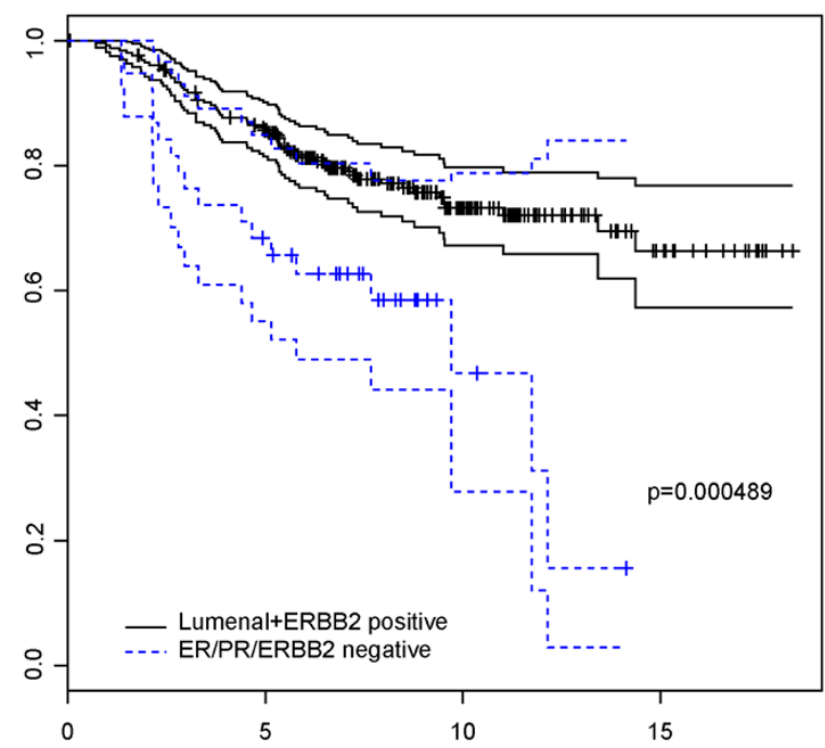

Survival analysis of the two sample clusters identified from the cancer data set [8]. The clusters were generated from the normal breast tissue signature. The estrogen receptor (ER)/progesterone receptor (PR)/ ERBB2 negative cluster consisting of $\mathbf{3 8}$ samples shows poor survival compared to the remaining samples consisting of Lumenal and ERBB2 positive tumors $(p=0.000489)$.

not selected as part of the intrinsic normal stroma signature, and thus we do not see association with prognosis when clustering using the intrinsic normal stroma genes.

A similar basal-like and normal-like cluster was identified using the intrinsic cancer gene set of Sorlie and colleagues [35]. This indicates that the basal-like and normal-like breast cancer subtypes are more similar to normal epithelial tissue than the other breast cancer subtypes. This is not entirely surprising, since normal ductal epithelium does not express high levels of ER, PR or HER2 [54,55]. When analyzed in a different cancer dataset, the basal-like subtype had a poor outcome when compared to other subtypes of breast cancer [35]. We also observed a poor outcome for the cluster of 38 ER/PR/HER2negative samples compared to the larger cluster of ER positive, and HER2 positive samples ( $p=0.000489$, Figure 10). We found that this difference in survival could be explained primarily by the ER status of the sample (data not shown). The similarity of the basal-like and normal-like breast cancer subtypes has previously been shown by gene expression studies $[10,11,35]$. We have found that these subtypes are distinguished from ER positive and HER2 positive subtypes, at least in part, by the expression of epithelium-specific genes. In contrast, the HER2 positive and luminal subtypes exhibit enriched expression of stroma-specific genes. However, elevated expression of stroma-specific genes is not ubiquitous across all luminal or HER2 positive samples, nor is it correlated with any identifiable tumor subtypes (Figures 8 and 9). Nonethe- less, these differences in stromal and epithelial expression drive the clustering of breast cancer subtypes using our normal breast tissue expression signature.

\section{Conclusion}

This study provides the first in depth analysis of gene expression in morphologically normal epithelium and stroma adjacent to breast cancers as well as from reduction mammoplasty specimens. Analysis of the gene expression profiles revealed that there are no significant differences between tumor derived and reduction mammoplasty derived tissue. The analysis of these expression profiles in other breast cancer datasets identifies a distinct HER2/ER/PR negative subcluster that corresponds to a mixture of basal-like and normal-like cancer subtypes and reveals molecular similarities between normal breast epithelium and basal-like breast tumors with poor outcome. Moreover, the lack of any cancer-associated patterns of gene expression in morphologically normal breast tissues will enhance our understanding of early changes involved in cancer initiation. Furthermore, these data provide a base for the interpretation of breast cancer molecular profiling experiments and for the discovery of novel prognostic markers.

\section{Competing interests}

The authors declare that they have no competing interests.

\section{Authors' contributions}

GF, SS, MP and MH wrote the paper. GF performed computational experiments and analyzed the microarray data. GF and FP performed quality control. SS established protocols for amplification and labeling of RNA isolated by LCM and supervised LCM, RNA isolation and labeling and microarray hybridizations. MS performed the immunohistochemistry experiments and collected the stroma cellularity data. $\mathrm{FH}, \mathrm{AO}$, and $\mathrm{KK}$ classified tissues for microdissection and reviewed the tissue pathology. BZ collected patient history. SM was instrumental in collecting tissue samples.

\section{Additional files}

The following Additional files are available online:

\section{Additional file 1}

A table listing $p$ values for tests of association between clinical variables and top-level clusters (red boxes, Figure 6 ) induced by clustering various subsets of the data. Only normal adjacent stroma shows top-level clusters with significant $p$ values by the bootstrap. None of the clinical variables were found to be correlated with either top-level clusters or statistically significant subclusters (data not shown).

See http://www.biomedcentral.com/content/ supplementary/bcr1608-S1.pdf 


\section{Additional file 2}

A table listing tissue specific predictors of clinical characteristics based upon gene expression in adjacent stroma. The poor quality of the predictors is readily visible from the error rate for the predictors in the first column of the table. The error rate is the fraction of times the predictor misclassifies a sample under crossvalidation. Predictors were trained using gene sets from class distinction using SAM or LIMMA. For some combinations of clinical characteristics and class distinction algorithm, no genes passed the filtering criteria, and no predictor could be trained. In such cases the rows are omitted from the table. The gene set size is the initial size of the candidate gene set from which a predictor is built. This set is also selected under crossvalidation. The training error is the rate of misclassification for samples included in the training set. The PAM cross-validation error rate reported by the PAM algorithm [30] does not account for the selection of the candidate gene set under cross-validation. The predictor size is the number of genes in the predictor.

See http://www.biomedcentral.com/content/ supplementary/bcr1608-S2.pdf

\section{Additional file 3}

A table listing tissue specific predictors of clinical characteristics based upon gene expression in adjacent epithelium. The poor quality of the predictors is readily visible from the error rate for the predictors in the first column of the table. The error rate is the fraction of times the predictor misclassifies a sample under crossvalidation. Predictors were trained using gene sets from class distinction using SAM or LIMMA. For some combinations of clinical characteristics and class distinction algorithm, no genes passed the filtering criteria, and no predictor could be trained. In such cases the rows are omitted from the table. The gene set size is the initial size of the candidate gene set from which a predictor is built. This set is also selected under crossvalidation. The training error is the rate of misclassification for samples included in the training set. The PAM cross-validation error rate reported by the PAM algorithm [30] does not account for the selection of the candidate gene set under cross-validation. The predictor size is the number of genes in the predictor.

See http://www.biomedcentral.com/content/ supplementary/bcr1608-S3.pdf

\section{Additional file 4}

A table listing complete clinical characteristics of patients in this study.

See http://www.biomedcentral.com/content/ supplementary/bcr1608-S4.pdf

\section{Additional file 5}

A figure showing hematoxylin and eosin staining of (a) a breast reduction specimen and (b) a histologically normal specimen from an invasive breast carcinoma patient.

See http://www.biomedcentral.com/content/ supplementary/bcr1608-S5.pdf

\section{Additional file 6}

A figure showing heatmaps of normal tissue expression profiles clustered using published gene signatures. (a) SFT signature, (b) DTF signature [36], (c) activated CSR signature, (d) inactive CSR signature [44].

See http://www.biomedcentral.com/content/ supplementary/bcr1608-S6.pdf

\section{Additional file 7}

A schematic outlining the gene set comparisons and filtering operations performed using the normal tissue signature and gene sets from published expression profiles. Circles denote gene sets, labeled by name and with their size. Numbers in brackets denote the size of a gene set after filtering for high variance genes $(\operatorname{Var}>1)$ in normal tissue; $7.36 \%$ of genes in the normal dataset have variance greater than 1. Intersections between gene sets as well as the size of filtered gene sets are labeled with $p$ values denoting the significance of the overlap (hypergeometric test), or the significance of overrepresentation of high variance genes $\left(\chi^{2}\right.$ goodness of fit test), respectively. The data were derived from the following sources: SFT/DTF (Additional file 6a,b) [36]; SAGE [33]; CSR (Additional file 6c,d) [44].

See http://www.biomedcentral.com/content/ supplementary/bcr1608-S7.pdf

\section{Additional file 8}

A complete list of tissue specific expression markers identified in this study.

See http://www.biomedcentral.com/content/ supplementary/bcr1608-S8.XLS

\section{Additional file 9}

A complete list of GO categories overrepresented by the normal epithelium and normal stroma gene signatures.

See http://www.biomedcentral.com/content/ supplementary/bcr1608-S9.xls

\section{Additional file 10}

A list of genes differentially expressed between cellular and pauci cellular fibrotic stroma clusters.

See http://www.biomedcentral.com/content/ supplementary/bcr1608-S10.xls 


\section{Additional file 11}

A list of GO terms overrepresented by genes

differentially expressed between cellular and pauci

cellular fibrotic stroma clusters.

See http://www.biomedcentral.com/content/

supplementary/bcr1608-S11.xls

\section{Additional file 12}

A figure showing principal component analysis of matched adjacent normal tissues. (a) Scree plot showing the percent of data variation explained by the first 10 principal components of the patient matched adjacent normal tissue. The common reference design accounts for $84.58 \%$ of variations in gene expression observed in the data (Additional file 13), while principal components 2 and 3 are explained by variations in gene expression associated with tissue type, and components 4 through 8 are explained by variations in gene expression between individuals. (b) Scatter plot of principal component two against principal component 3. These two dimensions suffice to summarize the between tissue variation observed in the data, as demonstrated by the clustering of epithelial samples on the right of the plot (red), and stromal samples on the left (black).

Analogously, in five dimensions, we can explain the variation between individuals. No other clinical characteristics were significantly associated with any principal components.

See http://www.biomedcentral.com/content/ supplementary/bcr1608-S12.pdf

\section{Additional file 13}

A figure showing the effect of the common reference design in principal component analysis. Data that exhibit no variation in gene expression corresponds to an expression matrix where each gene on each array has exactly the same expression level. A slightly more realistic case exists where each gene has a different expression level, but the expression is just random noise (left panel). The principal components each explain a similar, small amount of the total variation in the data. The case at the other extreme of the spectrum from the random noise example consists of perfectly correlated data with no noise, as might be imagined from ideal replicate arrays (middle panel). The variability in the data occurs from each gene having a different level of expression; however, that expression is identical across arrays. Only one principal component is necessary to capture all of the variation in the data. The third and most realistic case consists of correlated data with random noise. This closely resembles what is observed in the normal tissue dataset with a common reference design. The arrays are highly correlated, resulting in the first principal component explaining the majority of the observed variations, and the remaining variation distributed amongst the remaining components.

See http://www.biomedcentral.com/content/ supplementary/bcr1608-S13.pdf

\section{Acknowledgements}

We are grateful to $D$ Cernea and $N$ Bertos for comments on the manuscript, to $\mathrm{H}$ Chen and S Dumont for expert technical assistance and to Drs R Michel and D Haegert as well as D Hori, T Vilhena, L Pasyuk, and $C$ Palko-Condron. This work was supported by operating grants from the Quebec Breast Cancer Foundation to MP and SM. GF was supported by a studentship from the ClHR McGill University Cancer Consortium Training Award in Cancer Research. SS was funded in part with a fellowship from the Cedars Foundation, and MP is a Canadian Institutes of Health Research Senior Scientist.

\section{References}

1. Edwards BK, Brown ML, Wingo PA, Howe HL, Ward E, Ries LA, Schrag D, Jamison PM, Jemal A, Wu XC, et al.: Annual report to the nation on the status of cancer, 1975-2002, featuring population-based trends in cancer treatment. J Nat/ Cancer Inst 2005, 97:1407-1427.

2. Elston CW, Ellis IO: Pathological prognostic factors in breast cancer. I. The value of histological grade in breast cancer: experience from a large study with long-term follow-up. Histopathology 1991, 19:403-410.

3. Henson DE, Ries L, Freedman LS, Carriaga M: Relationship among outcome, stage of disease, and histologic grade for 22,616 cases of breast cancer. The basis for a prognostic index. Cancer 1991, 68:2142-2149.

4. Shek LL, Godolphin W, Spinelli JJ: Oestrogen receptors, nodes and stage as predictors of post-recurrence survival in $\mathbf{4 5 7}$ breast cancer patients. Br J Cancer 1987, 56:825-829.

5. Torregrosa D, Bolufer P, Lluch A, Lopez JA, Barragan E, Ruiz A, Guillem V, Munarriz B, Garcia Conde J: Prognostic significance 
of c-erbB-2/neu amplification and epidermal growth factor receptor (EGFR) in primary breast cancer and their relation to estradiol receptor (ER) status. Clin Chim Acta 1997, 262:99-119.

6. Brenton JD, Carey LA, Ahmed AA, Caldas C: Molecular classification and molecular forecasting of breast cancer: ready for clinical application? J Clin Oncol 2005, 23:7350-7360.

7. van 't Veer LJ, Dai H, van de Vijver MJ, He YD, Hart AA, Mao M, Peterse HL, van der Kooy K, Marton MJ, Witteveen AT, et al.: Gene expression profiling predicts clinical outcome of breast cancer. Nature 2002, 415:530-536.

8. van de Vijver MJ, He YD, van't Veer LJ, Dai H, Hart AA, Voskuil DW, Schreiber GJ, Peterse JL, Roberts C, Marton MJ, et al.: A geneexpression signature as a predictor of survival in breast cancer. N Engl J Med 2002, 347:1999-2009.

9. Ma XJ, Wang Z, Ryan PD, Isakoff SJ, Barmettler A, Fuller A, Muir B, Mohapatra G, Salunga R, Tuggle JT, et al:: A two-gene expression ratio predicts clinical outcome in breast cancer patients treated with tamoxifen. Cancer Cell 2004, 5:607-616.

10. Perou CM, Sorlie T, Eisen MB, van de Rijn M, Jeffrey SS, Rees CA, Pollack JR, Ross DT, Johnsen H, Akslen LA, et al:: Molecular portraits of human breast tumors. Nature 2000, 406:747-752.

11. Sorlie T, Perou CM, Tibshirani R, Aas T, Geisler S, Johnsen H, Hastie T, Eisen MB, van de Rijn M, Jeffrey SS, et al.: Gene expression patterns of breast carcinomas distinguish tumor subclasses with clinical implications. Proc Natl Acad Sci USA 2001, 98:10869-10874.

12. Ma X-J, Salunga R, Tuggle JT, Gaudet J, Enright E, McQuary P, Payette T, Pistone M, Stecker K, Zhang BM, et al:: Gene expression profiles of human breast cancer progression. Proc Natl Acad Sci USA 2003, 100:5974-5979.

13. Lakhani SR, Chaggar R, Davies S, Jones C, Collins N, Odel C, Stratton MR, O'Hare MJ: Genetic alterations in 'normal' luminal and myoepithelial cells of the breast. J Pathol 1999, 189:496-503.

14. Bissell MJ, Radisky D: Putting tumors in context. Nat Rev Cancer 2001, 1:46-54

15. McCawley LJ, Matrisian LM: Tumor progression: defining the soil round the tumor seed. Curr Biol 2001, 11:R25-R27.

16. Wiseman BS, Werb Z: Stromal effects on mammary gland development and breast cancer. Science 2002, 296:1046-1049.

17. Wernert N: The multiple roles of tumor stroma. Virchows Arch 1997, 430:433-443.

18. Sgroi DC, Teng S, Robinson G, LeVangie R, Hudson JR Jr, Elkahloun AG: In vivo gene expression profile analysis of human breast cancer progression. Cancer Res 1999, 59:5656-5661.

19. Luo L, Salunga RC, Guo H, Bittner A, Joy KC, Galindo JE, Xiao H, Rogers KE, Wan JS, Jackson MR, et al.: Gene expression profiles of laser-captured adjacent neuronal subtypes. Nat Med 1999, 5:117-122.

20. Finak G, Godin N, Hallett M, Pepin F, Rajabi Z, Srivastava V, Tang Z: BIAS: Bioinformatics Integrated Application Software. Bioinformatics 2005, 21:1745-1746.

21. Irizarry RA, Bolstad BM, Collin F, Cope LM, Hobbs B, Speed TP: Summaries of Affymetrix GeneChip probe level data. Nucleic Acids Res 2003, 31:e15.

22. Irizarry RA, Hobbs B, Collin F, Barclay YDB, Antonellis KJ, Scherf $U$, Speed TP: Exploration, normalization, and summaries of high density oligonucleotide array probe level data. Biostatistics 2003, 4:249-264.

23. Smyth GK, Speed T: Normalization of cDNA microarray data. Methods 2003, 31:265-273.

24. Yang YH, Buckley MJ, Speed TP: Analysis of cDNA microarray images. Brief Bioinform 2001, 2:341-349.

25. Suzuki R, Shimodaira $H$ : Pvclust: an R package for assessing the uncertainty in hierarchical clustering. Bioinformatics 2006, 22:1540-1542.

26. Gentleman RC, Carey VJ, Bates DM, Bolstad B, Dettling M, Dudoit $\mathrm{S}$, Ellis B, Gautier L, Ge Y, Gentry J, et al.: Bioconductor: open software development for computational biology and bioinformatics. Genome Biol 2004, 5:R80.

27. Ihaka RG: R: A Language for Data Analysis and Graphics. J Comput Graph Stat 1996, 5:299-314.

28. Smyth GK: Linear models and empirical Bayes methods for assessing differential expression in microarray experiments. Stat Appl Genet Mol Biol 2004, 3:Article3.
29. Tusher VG, Tibshirani R, Chu G: Significance analysis of microarrays applied to the ionizing radiation response. Proc Natl Acad Sci USA 2001, 98:5116-5121.

30. Tibshirani R, Hastie T, Narasimhan B, Chu G: Diagnosis of multiple cancer types by shrunken centroids of gene expression. Proc Natl Acad Sci USA 2002, 99:6567-6572.

31. Raychaudhuri S, Stuart JM, Altman RB: Principal components analysis to summarize microarray experiments: application to sporulation time series. Pac Symp Biocomput 2000, 5:455-466.

32. Smyth GK, Michaud J, Scott HS: Use of within-array replicate spots for assessing differential expression in microarray experiments. Bioinformatics 2005, 21:2067-2075.

33. Allinen $M$, Beroukhim R, Cai L, Brennan C, Lahti-Domenici J, Huang $\mathrm{H}$, Porter D, Hu M, Chin L, Richardson A, et al:: Molecular characterization of the tumor microenvironment in breast cancer. Cancer Cell 2004, 6:17-32.

34. Chang HY, Sneddon JB, Alizadeh AA, Sood R, West RB, Montgomery K, Chi JT, van de Rijn M, Botstein D, Brown PO: Gene expression signature of fibroblast serum response predicts human cancer progression: similarities between tumors and wounds. PLoS Biol 2004, 2:E7.

35. Sorlie T, Tibshirani R, Parker J, Hastie T, Marron JS, Nobel A, Deng $\mathrm{S}$, Johnsen H, Pesich R, Geisler S, et al:: Repeated observation of breast tumor subtypes in independent gene expression data sets. Proc Natl Acad Sci USA 2003, 100:8418-8423.

36. West RB, Nuyten DSA, Subramanian S, Nielsen TO, Corless CL, Rubin BP, Montgomery K, Zhu S, Patel R, Boussard TH, et al:: Determination of stromal signatures in breast carcinoma. PLoS Biol 2005, 3:e187.

37. Luzzi V, Mahadevappa M, Raja R, Warrington JA, Watson MA Accurate and reproducible gene expression profiles from laser capture microdissection, transcript amplification, and high density oligonucleotide microarray analysis. J Mol Diagn 2003, 5:9-14.

38. Patel OV, Suchyta SP, Sipkovsky SS, Yao J, Ireland JJ, Coussens PM, Smith GW: Validation and application of a high fidelity mRNA linear amplification procedure for profiling gene expression. Vet Immunol Immunopathol 2005, 105:331-342.

39. Rudnicki M, Eder S, Schratzberger G, Mayer B, Meyer TW, Tonko M, Mayer G: Reliability of t7-based mRNA linear amplification validated by gene expression analysis of human kidney cells using cDNA microarrays. Nephron Exp Nephrol 2004, 97:e86-e95.

40. Schneider J, Buness A, Huber W, Volz J, Kioschis P, Hafner M, Poustka A, Sultmann H: Systematic analysis of T7 RNA polymerase based in vitro linear RNA amplification for use in microarray experiments. BMC Genomics 2004, 5:29.

41. de Bruin EC, van de Pas S, Lips EH, van Eijk R, van der Zee MM, Lombaerts M, van Wezel T, Marijnen CA, van Krieken JH, Medema $\mathrm{JP}$, et al.: Macrodissection versus microdissection of rectal carcinoma: minor influence of stroma cells to tumor cell gene expression profiles. BMC Genomics 2005, 6:142.

42. Moinfar F, Man YG, Arnould L, Bratthauer GL, Ratschek M, Tavassoli FA: Concurrent and independent genetic alterations in the stromal and epithelial cells of mammary carcinoma: implications for tumorigenesis. Cancer Res 2000, 60:2562-2566.

43. Simon R, Radmacher MD, Dobbin K, McShane LM: Pitfalls in the use of DNA microarray data for diagnostic and prognostic classification. J Nat/ Cancer Inst 2003, 95:14-18.

44. Chang HY, Sneddon JB, Alizadeh AA, Sood R, West RB, Montgomery K, Chi J-T, van de Rijn M, Botstein D, Brown PO: Gene expression signature of fibroblast serum response predicts human cancer progression: similarities between tumors and wounds. PLOS Biol 2004, 2:E7.

45. Deng G, Lu Y, Zlotnikov G, Thor AD, Smith HS: Loss of heterozygosity in normal tissue adjacent to breast carcinomas. Science 1996, 274:2057-2059.

46. Forsti $A$, Louhelainen J, Soderberg $M$, Wijkstrom $H$, Hemminki $K$ : Loss of heterozygosity in tumor-adjacent normal tissue of breast and bladder cancer. Eur J Cancer 2001, 37:1372-1380.

47. Ellsworth DL, Ellsworth RE, Liebman MN, Hooke JA, Shriver CD: Genomic instability in histologically normal breast tissues: implications for carcinogenesis. Lancet Oncol 2004 5:753-758.

48. Kurose K, Hoshaw-Woodard S, Adeyinka A, Lemeshow S, Watson $\mathrm{PH}$, Eng C: Genetic model of multi-step breast carcinogenesis 
involving the epithelium and stroma: clues to tumor-microenvironment interactions. Hum Mol Genet 2001, 10:1907-1913.

49. Larson PS, de las Morenas A, Bennett SR, Cupples LA, Rosenberg CL: Loss of heterozygosity or allele imbalance in histologically normal breast epithelium is distinct from loss of heterozygosity or allele imbalance in co-existing carcinomas. Am J Pathol 2002, 161:283-290.

50. Leong KG, Hu X, Li L, Noseda M, Larrivee B, Hull C, Hood L, Wong $F$, Karsan A: Activated Notch4 inhibits angiogenesis: role of beta 1-integrin activation. $\mathrm{Mol} \mathrm{Ce} / \mathrm{Bio} / 2002$, 22:2830-2841.

51. Zeng Q, Li S, Chepeha DB, Giordano TJ, Li J, Zhang H, Polverini PJ, Nor J, Kitajewski J, Wang CY: Crosstalk between tumor and endothelial cells promotes tumor angiogenesis by MAPK activation of Notch signaling. Cancer Cell 2005, 8:13-23.

52. Chang HY, Nuyten DSA, Sneddon JB, Hastie T, Tibshirani R, Sorlie T, Dai H, He YD, van't Veer LJ, Bartelink H, et al.: Robustness, scalability, and integration of a wound-response gene expression signature in predicting breast cancer survival. Proc Natl Acad Sci USA 2005, 102:3738-3743.

53. Fan C, Oh DS, Wessels L, Weigelt B, Nuyten DS, Nobel AB, van't Veer LJ, Perou CM: Concordance among gene-expressionbased predictors for breast cancer. N Engl J Med 2006, 355:560-569.

54. Clarke RB, Howell A, Potten CS, Anderson E: Dissociation between steroid receptor expression and cell proliferation in the human breast. Cancer Res 1997, 57:4987-4991.

55. Petersen OW, Hoyer PE, van Deurs B: Frequency and distribution of estrogen receptor-positive cells in normal, nonlactating human breast tissue. Cancer Res 1987, 47:5748-5751. 